\title{
Dangerous disciplines: Understanding pedagogies of punishment in the neoliberal states of America
}

\author{
Christopher G. Robbins, Serhiy Kovalchuk
}

Abstract: Public schools deploy a range of processes and practices that help constitute the formation and legitimation of certain knowledges, relationships, skills, values and, ultimately, subjectivities. School discipline regimes are one of these practices. Exercising their power through pedagogical modes of address, these regimes are currently organizing relationships throughout school cultures that reflect the values and encourage role performances associated with neoliberal capitalism. This research paper describes and analyzes two widely used discipline regimes-zero tolerance/hyper-criminalization and positive behavior interventions and support (PBIS) - through Foucault's theories of governmentality and biopolitics. These two regimes provide mirror images of the primary modes of punishing and disciplining under neoliberalism: criminalization and individualization. The paper will also explore how neoliberalism subjects schools to processes of enclosure, but also how schools themselves have become sites productive of neoliberal subjects through the content, values and interests embedded in the curricula of PBIS and criminalization which students must master.

Key words: zero tolerance, criminalization, positive behavior interventions and support (PBIS), race, discipline, governmentality, neoliberalism, biopolitics

\section{Introduction}

Two seemingly disparate dynamics define U.S. public schools. On the one hand, a metrics fetish drives formal and informal education policy discourses and educational practices. Operating under what Giroux (2011) calls a "mindless logic of quantification and measurement" (p. 4), public schools seem to be almost solely concerned not with the development of curious 
or engaged learners or even with the "disciplining" of individuals, but with measuring, cataloging, and producing ever massive mounds of "data." The U.S. Secretary of Education, Arne Duncan (2009), has claimed that one of the most pressing challenges facing public schools is the production, interpretation, and explanation of "data". All other questions or concerns, say, with growing poverty rates for U.S. children coupled with egregiously large funding inequities across districts (Carter, 2012; Darling-Hammond, 2009; Hochschild \& Scovronick, 2004), are, according to Duncan, merely "ideological" and thusly should not occupy valuable public resources and time when attention could be given to non-ideological things like "data" (Duncan, 2009). Numbers do not lie. Duplicitous corporate education reformers and their bedfellows in government repeatedly command various publics to believe, as if sheer repetition of this partial truth would magically make it completely true. On the other hand, public schools, especially for many poor students and poor students of color, operate as feeder systems for the U.S.'s notoriously gargantuan prison-industrial complex as inexplicably large numbers of youth of color get tangled in the criminal justice system for mostly offenses, like being "disturbing," "insubordinate," or "disruptive" that are codified as intolerable violations in state and school level zero tolerance policies. While new forms of social exclusion (and highly probable subsequent social death) act on many students of color in both segregated and moderately integrated school contexts, pre-modern forms of public punishment and humiliation now get meted out with "postmodern" technologies, as demonstrated, for instance, by the expanding use of taser guns by police officers and school resource officers (SROs) on students (Robbins, 2011).

Yet, between these processes of measurement madness related to alleged academic indicators and the practices of punishment associated with criminalization, another set of processes and practices have emerged in recent years in U.S. public schools. School- (and district-) wide "behavior" programs, like Positive Behavior Interventions and Support (PBIS), dovetail in practice-in their effects-with the animating discourses, relationships, and practices associated with both the metrics fetish and drive to criminalize youth. Stemming from a behaviourist psychology, PBIS has extended from an approach of working with the students with disabilities who have behavioural problems to a school-wide behavioural intervention. It is a multilevel discipline intervention approach aimed at the proactive prevention of discipline issues through the formation of positive behaviours among students (Sugai \& Horner, 2002). PBIS focuses on the whole school as the unit of analysis addressing the social behavioural needs of all students and thus targeting them collectively, not individually. PBIS 'sells' itself as an effective instrument for decreasing problem behaviours and the suspension and 
expulsion rates, increasing time spent in academic instruction, and improving academic outcomes (Putnam, Holner \& Algozinne, 2006).

While one would be justified in turning to Foucault's theory of governmentality to analyze the ways by which pedagogy has been redefined in accordance with or as an effect of neoliberalist policies of "accountability," "efficiency," and standardization, others have already looked at these concerns in insightful ways (e.g., Scott, 2008; Giroux, 2003). When thinking of curriculum, one could also look at the specific changes made to curricular content and so-called content standards as policies put public schools under intensive accountability, or austerity, practices. Such work, too, provides rich insights on the varied ways by which neoliberal governmentality has integrated into educational policy, curriculum, and pedagogy. In looking specifically at PBIS and criminalization, we, however, want to draw from the notion of "hidden curriculum" as we consider possible issues associated with neoliberalism, governmentality, and "curriculum." Hidden curriculum can be understood as the knowledge, values, and learning that occurs through the organization of classroom and school relationships (Anyon, 1981; Apple, 2004; Bourdieu \& Passeron, 1977; Giroux, 1983). Implicit in this curriculum are "messages" about power, control, and authority. However, PBIS, with its graphic representation of student behaviors in classroom and school charts and explicit curriculum, and criminalization, with its obvious signs, symbols, and agents (e.g., metal detectors, police, surveillance cameras, etc.), do not "hide" their content or values and interests. Rather, such programs, processes and their constitutive relationships provide a "not-so-hidden curriculum," a curriculum on which students might not take a standardized test, but one they nonetheless must master. In our review of PBIS and overview of criminalization (something we believe to be the racialized undergirding of PBIS or neoliberal governmentality more generally), we would like to highlight key dimensions of Foucault's theory of governmentality, while focusing on Foucault's concerns with the ways that "programs" produce effects, sometimes unintentionally, that call into being new relationships and, consequently, new knowledges and new points of "regulation" and "intervention," thus pointing to the deeply pedagogical character of school relationships, hidden and not-so-hidden.

\section{The Politics of Discipline and Humiliation: Neoliberal Governmentality in Education}

If there is a distinctive feature of neoliberal governmentality, Foucault shows us that neoliberal governmentality entails a reorganization of poli- 
tics and the state, not an erosion of the state. This reorganization, per Foucault's theory of governmentality, is something that occurs, has to occur, on various levels of society, across domains in society, and in the representational systems of society, "covering the whole surface that lies between the organic and the biological, between body and population" (Foucault, 2003, p. 253). In his posthumously published lectures, Foucault (2003) explained that governmentality, unlike "discipline," is a technology that addresses a "multiplicity of [people]...to the extent that they form...a global mass" (p. 242). Governmentality concerns itself not with individual bodies or even groups of bodies, but with the "population as such" (p. 247). For this reason, Foucault argued that governmentality signals the "emergence of a power that [he] would call the power of regularization and it...consists in making live and letting die" (p. 247). Consequently, Foucault said that biopoliticsor, life politics-assumes a central position in governmentality because it deals with "the population as a political problem, as a problem that is at once scientific and political..." (p. 245). When the population itself is viewed as a scientific and political problem, the issues with which power concerns itself change. No longer is power concerned, at least as a primary and obvious point of intervention, with discipline as such. According to Foucault, problems of the traditional disciplinary character are "aleatory and unpredictable" but, when addressed at the "collective level," are "easy, or at least possible, to establish" (p. 246). This does not mean that discipline disappears. It, like the former state (and state of politics) with which it was associated, gets reorganized, redefined, rearticulated. One could say of discipline, as one could of a number of other responsibilities of the "state," that it has been outsourced, delegated to individuals, as a way of shaping the population through forcing individuals into ever greater relationships with the market or relationships that operate on the neoliberal market's codes of hyperindividualism, competition, and fragmentation.

The "mechanisms" that deal with these collective problems of population thusly become less interested with matters of control of bodies and behaviors, per se, than with the organization of the field in which actions take place. Governmentality and biopolitics is concerned with "forecasts, statistical estimates, and overall measures. (Foucalt, 2003, p. 246)

Language and discursive relationships also figure centrally in neoliberal governmentality and biopolitics, as Foucault detailed throughout his oeuvre more generally. Drawing upon the knowledge-power relationship so central to Foucault's work, Lemke (2000) argues that knowledge and reason 
are not an exterior instance, but an element of government itself which helps to create a discursive field in which exercising power is "rational." The concept of governmentality suggests that it is not only important to see if neo-liberal rationality is an adequate representation of society, but also how it functions as a "politics of truth", producing new forms of knowledge, inventing new notions and concepts that contribute to the "government" of new domains of regulation and intervention. (p. 8)

Recent transformations in both U.S. education policy (discourses) and educational practices clearly illustrate these concerns that Foucault elaborated already in the 1970s. Elements of governmentality such as governance by data, disciplining and technologies of the self, and humiliation as organizing value widely operate in educational practices, including recently emerging school-wide behavior programs like PBIS and longer-standing processes of criminalization.

Whether we look at the privileged space that measurement, operating euphemistically under the auspices of "educational psychology," occupies in devalued and demeaned colleges of education or we look at the coteries of test preparation companies, test-making companies, data-banking companies, and consulting companies associated with data management in public schools, it becomes clear that new notions and concepts have been "invented," contributing to the government of new domains of regulation and intervention, just as the role of the "state" has been reconfigured under neoliberalism. We might also add, in this regard, that "government" operates not only in and across new domains, but also on different registers of regulation and intervention within domains. LyNell Hancock (2012), for instance, details issues that emerged when New York City Public Schools decided to release its massive storehouse of data on "teacher effectiveness." Officials, themselves involved in promoting a "data-driven" system, even raised concerns about the veracity of the data and its validity in determining teacher quality. Do newspapers publish the demeaning rankings of teachers, knowing that the data is not nearly conclusive or valid? Do they publish the rankings and couple them with analyses of the charts? What about the data kings themselves-how do or should they explain that, after copious public funds were spent on producing and collecting (fallible) data and after abundant resources, symbolic and material, were dedicated to convincing people of the value of data, this particular body of data was mostly useless unless worked through extensive analysis and footnoted with caveats about how the data should be interpreted? Hancock explains that various newspapers struggled with these questions, some more ethically than others, and the 
officials themselves equivocated on tactics related to the dissemination and framing of the data. The point: "Data" already had its supporting strong discourses and truth effects; this particular data could not be ignored-no data should be, but specific groups of students, teachers, and their wider communities could be ignored, and they and others will continue to be ignored now that better systems of measurement need to be created to construct more valid measures of "teacher quality." Whether intentional or unintentional, the effect remains: Resources-power-will be allocated to data production, while responsibility for meeting outcomes (on fewer resources) will be delegated to ("ineffective") teachers.

It is equally clear that what Giroux (2011) calls a "politics of humiliation" is a constitutive element of neoliberal governmentality and biopolitics as they work through, on, and with (the help of) public schools. The politics of humiliation illuminates again the mutually constitutive character of knowledge and reason and how they produce a discursive field in which "exercising [a particular form of] power becomes 'rational" (Lemke, 2000, p. 9). Giroux (2011) defines the politics of humiliation and wider culture of cruelty in which it operates as "the institutionalization and widespread adoption of a set of values, policies, and symbolic practices that legitimate forms of organized violence against human beings and inexorably lead to hardship, suffering, and despair" (p. 14). These values inform practices and relationships in public schools and colleges of education that nurture an entirely unhealthy focus on "efficiencies," "targets," "outcomes," "indicators," and "productivity." Materializations of these values can be found in the orgy of test preparation materials, worksheets, practice tests, computerized practice tests, standardized tests, endless spreadsheets of "data," and hyper-behaviorist school discipline plans for both teachers and students (replete with data collection, spreadsheets, and stigmatization). Because of the inordinate value given to "accountability" and the alleged measures used in producing it, public schools invest their resources and relationships in an endless process of "means creation"-more tests, more measures to document results on tests, more tests of the validity of tests, more measures of the number of measures and systems used to measure measures, and things alike. The ends, in other words, have become the creation of more means. Thus, it is probably more accurate, pace Foucault, to say that such processes, in their constitution, deployment, extension, revision and articulation with yet other aspects of schooling, redefine the ends of public schools, producing yet another domain and register of "regulation and intervention." If the ends are to govern data rather than people, data must also become a considerable part of the means actual governance.

Foucault (2003) explained, "The norm is something that can be applied to 
both a body one wishes to discipline and a population one wishes to regularize" (p. 253). The relentless production of data, and incessant legitimation of data as the arbiter of value in public schools, obviously further normalizes data as such. It also produces "data norms" or "targets," even if only momentarily, until the targets, outcomes, and efficiencies, that is, norms, get redefined. Enter the politics of humiliation. To riff on Foucault, some data (aka teachers, schools, and students) will live-will be made to live, while some data (aka teachers, schools, and students) will be allowed to die. Since processes of norming do not operate in an ethical vacuum, data just cannot die. It has to die because other data must live, and some justification has to be provided: It was not "good" data--"The schools are inefficient;" "The teachers' union was too obstinate and protected lazy teachers;" "The teachers were trained poorly;" and so on and so forth (See, for example, New York Post, 2012). Hence, the politics of humiliation, which seems to pervade neoliberal governmentality from top-to-bottom as it has taken shape in the U.S. For there to be winners in a society constructed, at least in mythical terms, on egalitarian values of equal opportunity and meritocracy, the losers must not only be produced, but produced widely (thus the financial and political pummeling of them and their schools through defunding and "restructuring" or "takeover"), lurid images of their incompetence circulated vividly in newspapers, on newscasts, and in film ("documentaries" and dramas, alike). And, this circulation of images and discourses provides another domain and register of regulation and intervention: certain images of and discourses on teachers, students, and schools become the "dominant" ones, no matter how baseless, while other ones get elided, masked, submerged; and teachers and students daily modulate their behaviors and relationships in opposition to these images and discourses, lest they become part of the mosaic of educational malaise and malfeasance produced by public schools. The power of such images associated with the politics of humiliation is not that there is one or a few very "bad" teachers, but all teachers and, by extension, nearly all students - as a population, not as individuals—present a "political problem" of momentous proportions when "education" is essential for societal stability and competitive advantages in the global market at the same time public schooling must, per neoliberalism, be privatized, must itself be a political problem that challenges the neoliberal reorganization of the state.

\section{"Appropriate Behavior" or Population Management through PBIS}

PBIS is defined as "the application of positive behavioural interventions and systems to achieve socially important behaviour change" (Sugai et al., 
2000, p. 133). It was initially developed as an alternative to harsh interventions for changing problem behaviours of youth with developmental disabilities (Netzel \& Eber, 2003). Its introduction in educational policy and practice took place under the influence of amendments to the Individuals with Disabilities Education Act (IDEA) in 1997. These amendments required schools to take a proactive, problem-solving approach toward problem behaviours of students with disabilities to protect their rights, while expanding the authority of school officials to protect the safety of all children by maintaining orderly, drug-free, and disciplined school environments (Drasgow \& Yell, 2002).

In the recent years, PBIS has extended from working with the students with disabilities to a school-wide behavioural intervention for regularizing the school population. This transition took place under the influence of exaggerated discourses about school violence and safety and the "deviant" and "undisciplined youth," debates around how to deal with antisocial and disruptive behaviours of students in school settings, and the substitution of immediate reactive and exclusionary approaches with ones aimed at the development of positive social behaviours (Sugai \& Horner, 2002). PBIS argues that reactive and punishment-based responses create a false sense of security (ibid). For example, a review issued by the American Psychological Association (2008) indicates that zero tolerance policies have failed to achieve the goals of an effective system of school discipline and establish productive learning environments. It points at a number of issues produced by zero tolerance ranging from a negative relationship between the use of school suspension and expulsion and student academic achievement to the increasing use of profiling and the overrepresentation of minority students in suspension and expulsion (APA, 2008). Instead of zero tolerance, APA suggests using discipline models such as PBIS and Safe and Responsive Schools aimed at the proactive prevention of discipline issues through the formation of appropriate social behaviours among students. The shift from reactive to proactive discipline approaches is one of the effects produced by PBIS. However, in practice, PBIS still uses zero tolerance approaches toward at-risk and high-risk students.

Another effect produced by PBIS is a redefinition of authority of school officials and teachers in dealing with discipline. They have become a schoolwide orchestrators and watchdogs of students' behaviour. It is manifested in the structural implementation of PBIS and the role that school figures have to play. For example, "teachers must engage in active supervision ... so that students learn that teachers are monitoring and evaluating their social behaviours" (Sugai \& Horner, 2002, p. 34). The structural implementation entails: establishment of PBIS leadership team; gaining a school-wide sup- 
port among administrators, teachers, and staff; defining school-wide behavioural expectations based on a variety of data types (e.g., attendance and tardy patterns, office discipline referrals, detention, suspension, and expulsion rates, and behavioural incidence data); teaching behavioural expectations to students, developing procedures to acknowledge taught behaviours and discourage inappropriate ones; and monitoring and assessing PBIS outcomes (Lassen, Steele \& Sailor, 2006; Sugai \& Horner, 2002). Governance by data is a key in PBIS. Schools are encouraged to collect reliable and valid discipline data, have mechanisms for storing, manipulating, and summarizing data, and have structures for facilitating data-based decision making (Sugai \& Horner, 2002). Data is necessary both to show the effectiveness of the program and to tailor it, if necessary, in order to achieve better and continuous behavioural results in the interests of different stakeholders (e.g., teachers, parents, employers).

The third effect of PBIS is an emphasis on collective behaviours and focusing on the whole school as a unit of analysis. In order to enact a behavioural change, there is a need of targeting, molding, and controlling the whole school population, not particular individuals and not through a mere focus on basic behaviour and classroom management. This is done via the three conceptual levels of interventions: primary (i.e., universal), secondary (i.e., selected/targeted), and tertiary (i.e., intensive) (ibid). The goal of primary interventions is to inhibit the development of problem behaviours through the direct teaching and constant reinforcement of the behavioural expectations, maximize academic success, and remove the factors that contribute to problem behaviours. They are applied across all school and target approximately $80-90 \%$ of students. Students who are not responsive to the universal interventions are considered for secondary or tertiary levels. Secondary interventions are for those who demonstrate risk factors and who require more specialized forms of behavioural support. They provide additional skill instruction and can be implemented, for example, in the form of tutoring and mentoring programs (George, White \& Schlaffer, 2007). They approximately target $5-10 \%$ of student population. The tertiary level of interventions targets approximately $1-5 \%$ of students who have persistent behaviour problems and need an intensive behavioural support. These interventions are individualized and consist of functional behavioural assessment and comprehensive behavioural plan.

The most typical behaviours introduced to students are associated with responsibility, respect, order, complicity, obedience, and accountability (see the next section). These behavioural characteristics fit in the image of a neoliberal subject whose roles are redirected by neoliberal forces in a way that, on one hand, he or she is a compliant worker and politically passive citi- 
zen, and, on the other hand, an active consumer (Giroux, 1999). PBIS depoliticizes the rights of students as they do not have any say in behaviours which they must exhibit as well as their citizenship by equating it with a "good" and "effective" citizen. Despite the fact that schools have autonomy in outlining behavioural expectations, these expectations are almost the same across all schools which points at the "production" of individuals with the same behaviours and their collective governance. PBIS has been endorsed by the US Department of Education (Duncan, 2009), is being implemented in 16,323 schools, and it has a country-wide network with coordinators offering PBIS training to schools and the blueprints for its implementation and assessment (PBIS National Technical Assistance Center, 2012). The American Recovery and Reinvestment Act and other funding sources provide finance to form "appropriate" social behaviours among citizens via PBIS. Many states (e.g., Illinois, Maryland, Michigan, and others) initiated a statewide implementation of PBIS.

PBIS and zero tolerance preserve racial politics and racial order(ing) through the disproportionate use of discipline measures toward youth of color. For example, in their national investigation of African American and Latino disproportionality in school discipline, Skiba and his colleagues (2011) found that while PBIS reduced school exclusion for all students, African American and Latino students received more severe punishment for the category "minor misbehaviour" in comparison with their white peers.

The last important effect produced by PBIS is a spectacle of "good" behaviours. PBIS organizes a spectacle around public acknowledgement and celebration of "appropriate" behaviours exhibited by "good" students, for example, at weekly and monthly school assemblies. The practice of acknowledgement produces lasting effects on students slipping into their minds an idea that they can be recognized if they exhibit certain behaviours and also commodifies their behaviours contributing to the creation of consumerist individuals (see the next section).

\section{Student Criminalization, or a Schematic History of how some Students can now die}

In 1994, U.S. education policy and, ultimately, political culture turned a corner. As one part of the renewal of the Elementary and Secondary Education Act (1965) in Goals 2000: Educate America Act (1994), the U.S. federal government codified and mandated "zero tolerance" in the Gun-Free Schools Act. The act stated: 
No assistance may be provided to any local educational agency under this Act unless such agency has in effect a policy requiring the expulsion from school for a period of not less than one year of any student who is determined to have brought a weapon to a school under the jurisdiction of the agency. (for bibliography: Public Law 103-227, Gun-Free Schools Act (1994). SEC 1031, 20 USC 2701)

As inane and obvious as the policy appeared (most public schools already had policies on firearms, other weapons, and drugs and alcohol), the policy soon produced four primary effects. One effect was not necessarily the decline of youth violence or violence in schools, as reported acts of student violence had already shown signs of decline in the two years leading up to the law and violence itself, its sources, conditions of deployment, likely had been redefined as schools received legal support to promote the violence of exclusion with impunity. Thus, one of the first effects was an expansion and muddying of definitions of violence (Dunbar \& Villaruel, 2002). Like the sweeping use of zero tolerance that took hold of other social policies in the late 1980s and early 1990s, zero tolerance in schools grew into a far-reaching practice from which children have had criminal charges brought against them for social behaviors once deemed trivial or needling at best, deserving of a trip to the principal's office or a call to a parent/caregiver rather than a trip to the police station. Here, one can think of the widely publicized story of a first-grader who brought his Boy Scout eating utensil in his lunch, and his Maryland school district classified the utensil as a weapon, subjecting the boy to suspension and 45 days in reform school (Urbina, 2009). Emblematic of the absurd and punitive character of this policy and its related practices, events like this one happen regularly, as the majority of documented exclusions due to zero tolerance are for "disruptive" behaviors or behaviors defined as "disorderly conduct" alone, that is, violations that legal scholars would call "subjective offenses" that, by definition, can be open to a variety of interpretations, underpinned by all kinds of racialized, classed, and gendered assumptions about "appropriate" or "disorderly" behavior (Fancher, 2009; Mukherjee \& Fellow, 2007; Hirschfield, 2008).

As the expansion of the policy seemed to only justify wider public discourses of youth violence and criminality, the proliferation of school police, school resource officers (SROs), and a still burgeoning industry of school security technologies presented another set of effects of zero tolerance. Consider the following. In 1997, there were approximately 9500 active SROs, whereas by 2003 , approximately 14,300 SROs were on active duty (Petteruti, 2011, p. 6), a number that has continued to grow in the last decade. 
Over 1000 schools have their own police dogs, while many school districts in large cities have their own police departments. In addition to the increasing prevalence of police officers and SROS in public schools, surveillance technologies like CCTV and cameras, biometric scanning devices, tracking technologies, metal detectors and, now, tasers have occupied greater amounts of school space-and expenditures (Robbins, 2011).

It is thusly unsurprising that yet another primary effect of youth criminalization in schools has been social exclusion through suspensions and expulsions and the increasing administration of "school-based arrests." Nationally, schools have suspended upwards of 3 million students per year since 2002 (Planty et al., 2009). With the increasing presence of and responsibilities allocated to police officers and SROs in public schools to deal, seemingly, with traditional "discipline problems," school-based arrest of students has become a common practice. In his study of SROs and school-based arrests, Theoriot (2009) shows that $11.5 \%$ of students were arrested in schools with SROs versus a rate of $3.9 \%$ in schools without SROs. Given that SROs dedicate approximately $50 \%$ of their time to law enforcement activities, one would think that they have had to respond to criminal incidents. Theoriot shows not only that SROs mete out 8.5 of every 100 arrests for "disorderly conduct" (in legal terms, a broadly subjective category), while only 2.7 of every 100 arrests is for alcohol, drugs and assault combined. When controlling for student poverty (or strain), schools without SROs had an arrest rate of 1.8 of 100 arrests for "disorderly conduct" and 1.8 of 100 arrests for alcohol, drugs, and assault combined (p.282). The Advancement Project (2005) found that, between 2000-2004, Denver Public Schools (DPS) produced a $71 \%$ increase in student referrals to law enforcement (p.23), many of which landed students in juvenile court, with some leading to detention. Particularly illustrative in this case, $66 \%$ of referrals to law enforcement were for non-criminal violations and violations unaccounted for in the GFSA (1994). As the Advancement Project (2005) notes, the racial and ethnic (and class) dimensions of these referrals also can be clearly seen, where "in the 20032004 school year, Black students in [Denver Public Schools] were given tickets at twice the rate of White students, while Latino students were given tickets at seven times the rate of their White peers" (p.24). Fowler (2010) found, in an extensive study of criminalization in Texas schools, similar rates of referrals to the criminal justice system with the combination of increased police presence and Draconian definitions and applications of zero tolerance policies and other disciplinary measures. And this presents the fourth primary effect of youth criminalization: a redefinition of racial politics and racial order(ing) through the disproportionate deployment of criminalization on youth of color, as, on average, African American students are 3 times as 
likely to receive suspensions as their white counterparts in public schools (Lewin, 2012; see also Giroux, 2009).

\section{Governmentality and Biopolitics as Curriculum in U.S. School Disciplinary Regimes}

PBIS is a discipline model of behaviourist psychology which, in its turn, approaches students as passive, docile bodies requiring surveillance and monitoring, molds them to do the right thing, ignores context and conditions out of which they emerge, exercises 'one-size-fits-all' mentality, and manipulates them (Beyer, 1998). Behaviorists approach individuals both as the problem and the solution. Problems such as behavioural disorders, school difficulties, or unemployment are the results of a set of "risk factors" and individual deficiencies rather than the result of societal conditions (Dahlstedt, Fejes \& Schoenning, 2011). All individuals are at risk and schools are places where these problems can be detected, treated, prevented, and adjusted so that they will not represent social issues in the future. PBIS becomes a form of biopower used to instill in youth "positive" social behaviours required by a neoliberal order and deter them from behaviours that can threaten it. It entails both the governing by the state at a distance and the governing by individuals of their own mentality and interiority. This governing is implemented through a hierarchical observation, normalizing judgment, and examination (Foucault, 1995).

In PBIS, normalization takes place through school-wide behavioural expectations. Upon their introduction by teachers, students are expected to comply with them in a range of school settings (e.g., classroom, hallway, bathroom, playground). School expectations can be, for example: be respectful, be responsible, and be cooperative. Upon its translation into a classroom rule, the expectation of being respectful can entail: raise your hand and wait for permission to speak or leave your seat, and keep hands, feet and objects to yourself (Newcomer, 2009). One school developed a behavioral acronym RAFT where 'R' stands for respect others, self and property; 'A' always under control and always learn; ' $\mathrm{F}$ ' follow all direction, rules, and procedures; and ' $\mathrm{T}$ ' try your best all times (Hoey, 2009). In addition to teaching behaviours, another school also decided to display them on posters in hallways, cafeteria, main office, gymnasium, and each classroom visually targeting students' behaviour in multiple locations (Lassen et al., 2006). In one elementary school, students learned a chant about the proper way to walk through the halls.

Normalization deploys a number of instruments ranging from reinforcers to surveillance and exclusion to support and monitor its implementation. 
While aiming to facilitate compliance to certain behaviours, reinforcement can include social reinforcers (e.g., praise, recognition), activity reinforcers (e.g., special privileges, jobs, computer time), material reinforcers (e.g., tangible items), and token reinforcers (i.e., items exchanged for other reinforcers) (Newcomer, 2009). A common PBIS practice is to give students a slip, card, or school money in exchange for displaying desired behaviours. Some schools open 'stores' (George et al., 2007) where students can use received tokens to buy tangible items and thus create spaces for practicing consumerism and rearing a "democracy of consumers" (Giroux, 2000). In other schools, students can receive tickets which they submit to the school office for a weekly drawing. Winners of the drawing are called to the office to receive prizes and have their pictures taken and displayed in a trophy case (Lassen et al., 2006). Examples of prizes might include movie passes, coupons for fast-food restaurants, gift cards, homework passes, and other tangible items.

These forms of reinforcement can enable students to become "appropriate" individuals as they might do this to obtain a reward or compete with their peers for a number of slips, and also commodify their behavior. Students' behaviour becomes a product which they can exchange for "money" and tangible items. It becomes another item in a widespread market-oriented pedagogical practice which sends them a message that they can be rewarded if they exhibit appropriate behaviours and possess necessary skills whether they are in school, in a labour market or somewhere else. While being normalized, students are also individualized (when they exhibit their personal behaviours) and totalized (when their behaviours are compared, inspected, and evaluated according to the school behavioural expectations).

Surveillance or observation in PBIS is conducted both by school figures and students themselves. PBIS encourages teachers, administrators, and staff to scan (keeping head up and looking for rule following and violating behaviours), move (move through locations where expected behaviours are hard for students to demonstrated and where large numbers of students are present), and interact (make positive and preventive contacts with as many students as possible) (Sugai $\&$ Horner, 2002, p. 35). This model of supervision creates an effect of panopticon under the influence of which students can begin to exhibit behavioural expectations, even when they are not observed. In one high school, superintendent and principal observed students eating their lunch outside, discarding their leftovers into bags, and walking across the street to throw the bags into a trash can. They approached students and handed them orange cards if they adhered to a cleaning procedure. Students also surveil themselves by observing each other's behaviours. In elementary schools, students can watch how their names, along with the 
names of their peers, move up or down on a colour coded behavioural chart and what rewards and punishments they can receive for displaying or not desired behaviours. They can also, for example, watch their peers retrieving color cards from a wall chart which signify different levels of behavioural infractions (George et al., 2007). In other words, students begin to conduct both their own behaviour and the behaviour of others.

Despite its call against restraining and secluding, PBIS practices exclusion. Foucault (1995) stated, "all behaviour falls in the field between good and bad marks, good and bad points" (p. 180). Behaviours falling in the field of bad marks and points are subjected to punishment, exclusion or modification. An exclusionary nature of PBIS is manifested through its behavioural spectrum consisting of three levels of intervention. By labeling students as normal, at-risk or high-risk according to the set behavioural expectations and moving them from one to another level of intervention, PBIS conducts an exclusion of individuals who do not behave "appropriately" both for schools and wider neoliberal order using softer measures of punishment in comparison to those in criminalization and places them in more advanced levels of behavioural modification.

PBIS represents one of the aspects of the state reorganization by neoliberal governmentality, and it is aimed proactively to regularize the population in line with the needs and ideals of a wider society governed by a market ideology. It has become a disciplinary curriculum that teaches students "appropriate" behaviours and disciplines them for their adulthood where a possession of "appropriate" behaviours, attitudes, and skills can result in a financial reward. While schools are tasked to teach behaviours and create stimuli for their exhibition and cultivation, it is an individual responsibility of each student to adhere to them. If they choose not to do so, they might run a risk of being labeled as the "others," the unwanted and undesired citizen, and placed in more advanced levels of behavioural modification (Dahlstedt et al., 2011).

Especially given the U.S.'s racial history, racial politics does not disappear under neoliberal governmentality and its associated disciplinary regimes in public schools. Racial politics get reorganized and rearticulated. Foucault clearly explained the seemingly contradictory role that racism played in governmentality. If governmentality was concerned with the population as such as a "political and scientific" problem, then how could racism-the racial targeting, demeaning, disadvantaging, and devaluing of another group within the population-act in the interests of governmentality? What effects does the racist program of criminalization of students serve?

One must be careful, as Foucault himself was, to identify the ways that governmentality, despite its global dimensions and pretensions, develops in 
particular contexts and consequently must interact, negotiate, with existing relationships, discourses, and histories. As Goldberg $(2002 ; 2009)$ has provocatively detailed, racisms and racialist programs differ widely from society to society and from period to period within societies, ultimately reflecting "state character." In the case of "post-civil rights" U.S., Goldberg (2009) calls the U.S. brand of racial neoliberalism, "racial Americanization." Racial Americanization, for Goldberg, fuses a strange admixture of the effects of historic, explicit state commitment to racism and racialist policies with state non-commitment, or "colorblindness." Commitments to colorblindness, ironically, have resulted in active state efforts to undo anti-racist policies that were relatively recently inscribed in the state through civil rights legislation. If the state, and society more generally, is "colorblind," then how can it support policies aimed as racial redress? As part of the wider social state apparatus, civil rights commitments get squeezed as the neoliberal state sheds its social support commitments. State-based "racial neutrality" couples with neoliberal individualism and "conserves (and deepens) the hold of racial preference schemes historically produced as if they were the nature of things" (Emphasis in original, Goldberg, 2009, p. 78). Drawing upon the privatization of social risks, racial Americanization "privatizes" race and racism, attempting to hide ongoing racist commitments in individualist rational choice schemes that the state itself helps to (racially) order.

Foucault (2003) argued more generally in this regard that racism provides a form of biopower essential to governmentality. If governmentality is concerned with both the scientific and political characteristics of the "population as a problem" and must be concerned with the power to make live, racism helps "to fragment, to create caesuras with the biological continuum addressed by biopower" (p. 255). For this reason, Foucault argued, racism functions "to allow the establishment of a positive relation of this type: "The more you kill, the more deaths you will cause' or 'The very fact that you let more die will allow you to live more" (p. 255). He then argues that while this relationship has a war-like or political character, its introduction helps establish (discursively) a "biological-type relationship" where "races" can be deemed inferior or superior (p. 255), "threats, either external or internal, to the population and for the population" (p. 256) and, as threats, allowed to "die," if not subjected directly to death. Foucault was also clear in this regard that death did not necessarily entail physical death, nor did making live mean that my or your life as individuals is made better by the "death" of others. Rather, death signifies "exposing someone to death, increasing the risk of death for some people or, quite simply, political death, expulsion, rejection, and so on" (p. 256), and this exposure to death, increased risk of 
death, and/or political/civic death operates as something that makes life for the population itself better.

Given the consumerist and hyper-instrumentalist character of U.S. public schooling under neoliberal governmentality, some "problems" of population simply cannot enter into, or be entertained by, dominant discourses and their supporting relationships. As the government further scarcifies public funds for schools and orders them in competitive consumerist programs, some students can go to school, and some students cannot. Perhaps, the curricula of PBIS and criminalization, in their racially disparate application, create relationships in schools in which some students (or consumers) behave or can be seen to behave "appropriately"-appropriately for both schools and wider neoliberal order more generally-and other students behave "criminally," and thus allowed to receive greater exposure to or risk of civic death as they are removed from schools and, in increasing instances, from their civic communities more generally.

\section{Conclusion}

Concluding this paper on the current school discipline regimes in the U.S, we turn to concerned educators and ask them to consider the curriculum of criminalization as it operates primarily on populations of color, while individualist, consumer-oriented behaviorist programs seemingly provide another "curriculum" for other students. What do both groups learn as historic effects of racist commitments get buried in legalistic and individualist terms of "disruptive" behaviors? What knowledges do the students themselves create in the process of participating in these social relationships of consumerist individualism that undergird governmentality and its related "biopolitics of disposability" (Giroux, 2009) in schools and wider communities? When some students have behavior problems and other students appear as problems for the (school) population, what other domains of regulation and intervention come into being? As Foucault (1977) detailed in Discipline and Punish in relation to the invention of the prison, have schools now become the hub of production, or at least entrepot, for assembling and circulating new threats within the population or expanding the perceived scope of extant threats within the population? ${ }^{1}$

1 We would like to thank to the editor of this special issue whose feedback helped to improve this paper. 


\section{References}

Advancement Project. (2005). Education on lockdown: The schoolhouse to jailhouse track. Washington, DC: Advancement Project

American Psychological Association- APA (2008). Are zero tolerance policies effective in the schools?: An evidentiary review and recommendations. American Psychologist, 63(9), 852-862.

Anyon, J. (1981). Social class and the hidden curriculum of work. Journal of Education, 162(1), 67-92.

Apple, M. W. (2004). Ideology and curriculum (3rd ed.). London, UK: Routledge.

Beyer, L. E. (1998). "Uncontrollable students eventually become unmanageable": The politics of classroom discipline. In R. E. Butchart \& B. McEwan (Eds.), Classroom discipline in American schools: Problems and possibilities for democratic education (pp. 51-81). Albany, NY: State University of New York Press.

Bourdieu, P., \& Passeron, J. (1977). Reproduction in education, society, and culture. Beverly Hills: Sage.

Carter, P.L. (2012). Stubborn roots: Race, culture, and inequality in U.S. and South African schools. NY: Oxford University Press.

Dahlstedt, M., Fejes, A., \& Schoenning, E. (2011). The will to (de)liberate: Shaping governable citizens through cognitive behavioural programmes in school. Journal of Education Policy, 26(3), 399-414.

Darling-Hammond, L. (2009). The flat world and education: How America's commitment to equity will determine our future. NY: Teachers College Press.

Drasgow, E., \& Yell, M. L. (2002). School-wide behaviour support: Legal implications and requirements. In J. K. Luiselli \& C. Diament (Eds.), Behavior psychology in the schools: Innovations in evaluation, support, and consultation (pp. 129-145). The Haworth Press, Inc.

Dunbar, C., \& Villarruel, F.A. (2002). Urban school leaders and the implementation of zero tolerance policies: An examination of its consequences. Peabody Journal of Education 77(1). 82-104.

Duncan, A. (2009). Secretary Arne Duncan calls for honest answers about education reform. Retrieved June 5, 2012 from www2.ed.gov/news/av/video/youtube/honestanswers.doc

Duncan, A. (2009). Key policy letters signed by the Education Secretary or Deputy Secretary. Retrieved May 30, 2012 from http://www2.ed.gov/policy/elsec/guid/ secletter/090731.html

Fancher, M. P. (2009). Reclaiming Michigan's throwaway kids: Students trapped in the school-to-prison pipeline. Detroit, MI: ACLU.

Foucault, M. (2003). "Society must be defended:" Lectures at the college de France 1975-1976. NY: Picador.

Foucault, M. (1995). Discipline and punish: The birth of the prison. New York: Vintage Books. 
Fowler, D. (2010). Texas' school-to-prison pipeline: Ticketing, arrest, and use of force in schools-how the myth of the "Blackboard Jungle" reshaped school disciplinary policy. Austin, TX: Texas Appleseed.

George, M. P., White, G. P., \& Schlaffer, J. J. (2007). Implementing school-wide behavior change: Lessons from the field. Psychology in the Schools, 44(1), 41-51.

Giroux, H.A. (2011). Education and the crisis of public values: Challenging the attack on teachers, students, and public education. NY: Peter Lang.

Giroux, H.A. (2009). Youth in a suspect society: Disposability or democracy? NY: Palgrave.

Giroux, H.A. (2003). The abandoned generation: Democracy beyond the culture of fear. NY: Palgrave.

Giroux, H.A. (2000). Stealing innocence: Youth, corporate power and the politics of culture. Basingstoke, UK: Palgrave.

Giroux, H. A. (1999). Corporate culture and the attack on higher education and public schooling. Bloomington: Phi Delta Kappa Educational Foundation.

Giroux, H.A. (1983). Theory and resistance in education: A pedagogy for the opposition. Westport, CT: Begin \& Garvey.

Hancock, L. (2012). When big data is bad data: The press and standardized testing numbers: A cautionary tale. Columbia Journalism Review. Retrieved May 30, 2012, from http://www.cjr.org/behind_the_news/the_press_and_standardized_tes.php

Hirschfield, P.J. (2008). Preparing for prison? The criminalization of school discipline in the USA. Theoretical Criminology, 12(1), 79-101.

Hochschild, J.L., \& Scovronick, N. (2004). The American dream and the public schools. NY: Oxford University Press.

Hoye, S. (2009). Positive behavior proves productive in school. NBC Connecticut. Retrieved December 12, 20112, from http://www.nbcconnecticut.com/news/local/ Positive-Behavior-Proves-Productive-in-School.html.

Lassen, S. R., Steele, M. M., \& Sailor, W. (2006). The relationship of school-wide positive behaviour support to academic achievement in an urban middle school. Psychology in the Schools, 43(6), 701-712.

Lemke, T. (2000). Foucault, governmentality, and critique. Paper delivered at Rethinking Marxism Conference, University of Amherst (MA), September 21-24, 2000. Retrieved May 30, 2012, from http://www.andosciasociology.net/resources / Foucau $1 \mathrm{t} \$ 2 \mathrm{C}+$ Governmentality $\$ 2 \mathrm{C}+$ and+Critique+IV-2.pdf

Lewin, T. (2012). Black students face more discipline, data suggests. New York Times. Retrieved June 15, 2012, from http://www.nytimes.com/2012/03/06/education/ black-students-face-more-harsh-discipline-data-shows.html?_r=2\&ref=education

Mukherjee, E., \& Fellow, M.M.K. (2007). Criminalizing the classroom: The over-policing of New York City public schools. NY: ACLU.

Netzel, D. M., \& Eber, L. (2003). Shifting from reactive to proactive discipline in an urban school district: A change of focus through PBIS implementation. Journal of Positive Behaviour Interventions, 5(2), 71-79. 
Newcomer, L. (2009). Universal positive behavior support for the classroom. PBIS Newsletter, 4(4). Retrieved June 17, 2012, from http://www.pbis.org/pbis_newsletter/volume_4/issue4.aspx

New York Post. (2012). Editorial: Teacher-protection racket. Retrieved January 28, 2012, from http://www.nypost.com/p/news/opinion/editorials/teacher_protection_racket_wqMxiho2IAGswg0XB3ZYoI

Petteruti, A. (2011). Education under arrest: The case against police in schools. Washington, D.C.: Justice Policy Institute.

Planty, M., Hussar, W., Snyder, T., Kena, G., KewalRamani, A., Kemp, J., Bianco, K., \& Dinkes, R. (2009). The condition of education 2009 (NCES 2009-081). National Center for Education Statistics, Institute of Education Sciences, U.S. Department of Education. Washington, DC.

Public Law 103-227. (1994). Gun-free schools act. SEC 1031, 20 USC 2701

Putnam, R. F., Horner, R. H., \& Algozzine, R. (2006). Academic Achievement and the implementation of school-wide behavior support. PBIS Newsletter, 3(1). Retrieved June 20, 2012, from http://www.pbis.org/pbis_newsletter/volume_3/issue1.aspx Robbins, C.G. (2008). Expelling hope: The assault on youth and the militarization of schooling. Albany, NY: SUNY Press.

Robbins, C.G. (2011). Tased and confused: From social exclusion to shock in the war on youth. In K. Saltman \& D. Gabbard (Eds.), Education as enforcement: The militarization and corporatization of schools (pp. 114-129, 2nd ed.). NY: Routledge.

Scott, T. (2008). "Happy to comply:" Writing assessment, fast-capitalism, and the cultural logic of control. The Review of Education, Pedagogy, and Cultural Studies, 30(2), 140-161.

Skiba, R. J., Horner, R. H., Chung, C.-G., Rausch, M. K., May, S. L., \& Tobin, T. (2011). Race is not neutral: A national investigation of African American and Latino disproportionality in school discipline. School Psychology Review, 40(1), 85-107.

Sugai, G., \& Horner, R. (2002). The evolution of discipline practices: School-wide positive behaviour supports. In J. K. Luiselli \& C. Diament (Eds.), Behavior psychology in the schools: Innovations in evaluation, support, and consultation (pp. 23-50). The Haworth Press, Inc.

Sugai, G., Horner, R., Dunlap, G., Heineman, M., Lowis, T., Nelson, C., Scott, T., Liaupsin, C., Sailor, W., Turnbull, A., Turnbull, H., Wickham, D., Reuf, M., \& Wilcox, B. (2000). Applying positive behavioral support and functional behavioral assessment in schools. Journal of Positive Behavioral Interventions, 2(3), 131-143.

Theriot, M.T. (2009). School resource officers and the criminalization of student behavior. Journal of Criminal Justice 37(3), 280-287.

Urbina, I. (2009). "It's a fork, it's a spoon...it's a weapon? New York Times. Retrieved May 30, 2012, from http:/ /www.nytimes.com/2009/10/12/education/12discipline. html?_r=1 


\section{Authors:}

Christopher G. Robbins, Associate Professor

Eastern Michigan University

Department of Teacher Education

313 Porter Building

Ypsilanti

MI 48197

USA

email: crobbin2@emich.edu

Serhiy Kovalchuk, Ph.D. Candidate

University of Toronto

Ontario Institute for Studies in Education

Department of Curriculum, Teaching and Learning

252 Bloor St West, Office 10-125

Toronto

Ontario

M5S 1V

Canada

email: serhiy.kovalchuk@utoronto.ca 